Z Gerontol Geriat 2021 · 54:753-758

https://doi.org/10.1007/s00391-021-01995-4

Received: 17 September 2021

Accepted: 21 October 2021

Published online: 23 November 2021

( $\odot$ The Author(s), under exclusive licence to

Springer Medizin Verlag $\mathrm{GmbH}$, ein Teil von

Springer Nature 2021

Q

$\substack{\text { check tor } \\ \text { upodates }}$
(n)

\section{Massage and touch-based therapy}

\author{
Clinical evidence, neurobiology and applications in older \\ patients with psychiatric symptoms
}

Daniel Kopf

Klinik für Geriatrie, Endokrinologie und Diabetologie, Geriatrischer Schwerpunkt, RKH-Kliniken Ludwigsburg/Bietigheim, Bietigheim-Bissingen, Germany

\section{Abstract}

\section{In this article}

- Introduction

- Clinical applications of massage and touch-based treatment in clinical trials

- C-fibers and the affective touch system

- Implications for touch-based therapy in psychiatry of old age

- Conclusion

Background: Massage and touch-based treatment are popular despite limited evidence from high quality clinical trials. This article reviews the rationale and evidence of treating older patients with psychiatric symptoms by touch-based therapy.

Methods: Narrative literature review, based on Medline search with the following key words: massage, social touch, affective touch, clinical trial, meta-analysis. Citations of identified articles were searched for additional relevant studies.

Results: Evidence from clinical trials in adult patients with mainly chronic disorders of the musculoskeletal system suggests that massage therapy results in significant short-term improvement of symptoms; however, treatment effects appear not to be sustained. In addition, conclusions are difficult to draw owing to very heterogeneous study interventions, difficulties with definition of control conditions and treatment outcomes. There appears to be better evidence for improvement of psychological variables and subjective symptoms, such as pain and quality of life. A neuronal system of affective and social touch has been identified with specific afferents from C-fibre coupled low threshold mechanoreceptors projecting into the insular cortex and the limbic system. This system may also mediate effects of massage in adult patients. Positive clinical trials for depressive symptoms of dementia and for behavioral symptoms of advanced dementia are available with encouraging results.

Conclusion: The neuronal system of social and affective touch suggests a potential mechanism of action of touch-based interventions in geriatric psychiatry. In addition, it provides a rationale for applying and designing novel touch-based treatment strategies as adjunctive treatment for psychiatric disorders of old age.

\title{
Keywords
}

Dementia - Mechanoreceptors · C-fibers · Social touch · Geriatric depression

\section{Introduction}

Touch-based treatment is one of the oldest types of therapeutic intervention. It is documented in virtually all ancient cultures, ranging from ancient China, Japan, Persia, Egypt to Greece and the Roman culture [13]. Unlike other ways of medical treatment, such as pharmacological or surgical approaches, touch-based treatment is not limited by the availability of pharmaceutical products or surgical instruments, making it easily and broadly available. This may in part explain why touch- based treatments have frequently been developed outside or independent of the boundaries of the medical profession and of academic institutions. Many treatment methods have been based on individual experiences of charismatic founding fathers. Sometimes even new professional schools with own curricula have been built up.

This history has contributed to a very broad variety of available treatment concepts, which have been conveyed in specific schools; however, exchange of knowledge and skills between schools has been 
limited. The assessment of clinical efficacy, indications and limitations of treatment methods has frequently been based on personal experience of founding fathers rather than on prospective systematic evaluation. This has hampered thorough scientific evaluation. Despite these limitations, touch-based interventions are very well accepted by patients. Frequent indications and clinical applications are disorders of the musculoskeletal systems and chronic pain syndromes. Common to these disorders is a focus on subjective well-being and quality of life. Potential mechanisms of action include but extend well beyond direct mechanical manipulation of the skin and underlying tissue. Cutaneovisceral reflexes have long been discussed [9]; however, in the absence of evidence from high quality clinical trials to support this hypothesis, the physiology of touch-based interventions has long remained in the dark.

Recently, the award of the Nobel Prize in Physiology or Medicine has placed the physiology of touch perception into the light of public interest [16]. In addition, the coronavirus disease 2019 (COVID-19) pandemic has highlighted the importance of human touch for well-being, stress reduction and immunity [2]. Progress in neurobiology has led to the description of various types of cutaneous mechanoreceptors including their neuronal pathways of information processing [1]. Identification, molecular and functional description of mechanoreceptors have furthered a new understanding of sensory perception [11]. A specific subtype of mechanoreceptors linked to $C$ fibres is involved in emotional processing of touch perception and has been shown to play important roles in human development, health and well-being $[6,19]$.

This newly established biological connection of touch and regulation of emotion may provide an explanation for the effects of massage therapy on subjective well-being and emotional stress reduction. The findings also give a good reason for a re-appraisal of touch-based interventions in psychiatric disorders. This brief review gives an overview of clinical applications of massage therapy, then moves on to the underlying pathophysiology of social and affective touch and addresses some implications for treatment of psychiatric disorders in old age by touch-based therapy.

\section{Clinical applications of massage and touch-based treatment in clinical trials}

Applications in the field of musculoskeletal disorders and pain Not surprisingly, massage therapy is broadly used in sports medicine, particularly to treat strain-induced muscle soreness and muscle injury. A meta-analysis has shown statistically significant but clinically modest effects on pain in this condition [26]. Different types of massage therapy have been applied in patients with specific joint pain of various joints with mild or moderate effects. A thorough review was presented by Field [7]. Most studies are available for chronic low back pain. In this condition, in which massage has been applied very often, significant beneficial effects were obtained in the short-term follow-up [8]. Unfortunately, effects do not appear to be very sustained.

Applications in palliative care With the rise of palliative care, touch-based therapy continues to be applied very often in end of life situations. In this setting, where quality of life is the major treatment goal, various studies are available. Interpretation and comparison of study results are difficult because frequently various treatment approaches, such as massage, aroma therapy, meditation techniques and other modalities were combined. In addition, settings and underlying diagnoses vary. Thus, a current systematic review does not unequivocally demonstrate efficacy of massage therapy in this setting [4]. Studies also suffer from ill-defined and mixed endpoints, such as pain, anxiety, quality of life and other well-being related endpoints.

Evaluation of massage therapy vs. control groups A very recent meta-analysis concluded that compared to sham therapy, massage therapy does not add significant clinical benefit [15]. This points to a problem in scientific evaluation of massage therapy: blinding is not possible because patients will easily recognize to which treatment arm they have been allocated. If at all, blinding is possible, if sham therapy closely resembles active treatment. If the effect of touch-based treatment is conveyed by touch itself, not by a specific therapeutic type of massage, sham treatment will be effective as well, thus concealing the effects of the so-called active intervention. This finding may give rise to the hypothesis that effects of massage therapy are not highly specific but that nonspecific interventions, for example personal contact to a caring person or nonspecific ways of touching, are equally effective. Alternatively, it may be hypothesized that the specific type of intervention in some control conditions may more specifically address physiological pathways than the specific type of school-based massage technique. In addition, short-term relief may be cherished by patients suffering from chronic pain even in the face of the fact that treatment effects are not sustained. These factors may also explain why effectiveness appears to be higher in fibromyalgia, a chronic pain condition where psychological factors are particularly pronounced [17].

In summary, massage therapy appears to be widely used in different conditions with the intention to reduce pain and improve general well-being. Beneficial treatment effects have been demonstrated; however, in many indications evidence is not very robust. Studies are of heterogeneous quality. A problem with systematic evaluation is heterogeneity of treatment options and not very well-defined endpoints; however, it appears that treatment effects are more pronounced on subjective, psychological and quality of life-oriented endpoints.

This observation from many studies suggests that massage therapy exerts its effects by complex modulation of cognitive and emotional perception rather than by local musculoskeletal effects at the treatment site.

More recent evidence in pregnancy and perinatal care In recent years, neonatal care of preterm infants has evolved as a setting for adjunctive use of massage therapy, with convincing evidence. In pregnancy, studies have been found to be somewhat more consistent. Positive effects of massage include reduced 
Hier steht eine Anzeige.

黑 Springer 


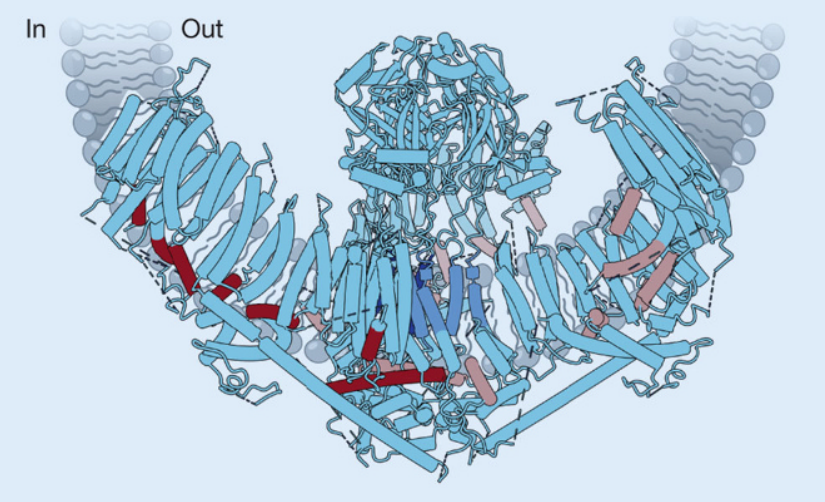

Fig. $1 \Delta$ Molecular structure of the PIEZO1 mechanoreceptor. The mechanoreceptor represents a mechano-sensitive ion channel. The pore lining sequences are displayed in dark blue and cornflower blue in the center of the molecule (from [11] with kind permission of Susanne Denskus from Springer Heidelberg)

stress, back and leg pain, depression and anxiety; increased immune response; increased serotonin and dopamine levels; higher fetal birth weight and reduced risk of preterm delivery [21].

Even more solid biological endpoints have been shown to be positively affected by massage therapy. A recent meta-analysis reported improved weight gain in controlled randomized studies involving preterm infants with very low birth weight or low birth weight [18]. One recent randomized controlled study even showed that the stay on a newborn intensive care unit was even reduced by 5 days, when a short 5-day course of moderate pressure massage therapy was applied [25]. An earlier Cochrane meta-analysis already came to similar results but concluded that low quality of included studies and potential reporting bias did not allow a positive recommendation to apply massage [28]; however, the fact that methodological details (low pressure vs. moderate pressure, massage with or without oil etc.) appear to make a difference in study outcomes, lends credit to the validity of study findings. Again, these findings point to a mechanism of action which is likely mediated by complex neuronal processing of somatosensory input.

\section{C-fibers and the affective touch system}

Indeed, modern neurobiology has deciphered neuronal pathways of tactile per- ception which are in crosstalk with the limbic system and with the autonomic nervous system. Those pathways can interfere with neuronal development. The sensory basis of these pathways appears to be peripheral C-fiber-coupled low threshold mechanoreceptors (C-LTMR) [1]. Receptors have been characterized as ion channels which respond to mechanical strain (• Fig. 1). In humans, these receptors correspond to so-called $C$ tactile afferents or CT afferents. While this type of receptor has primarily been described in the context of painful stimuli, more recent research has shown that this cell population is also found in hairy skin in connection with the hair follicle. Here, it transmits signals originating from gentle touch, resulting in deflection of hair. Information processing in the spine differs accordingly between various mechanoreceptor populations, leading to at least partially distinct pathways for processing of discriminative touch, painful stimuli and stimuli involved in social touch situations. Stimulation of unmyelinated $\mathrm{CT}$ afferents projects to the insular cortex, bringing it in close contact to brain areas involved in the processing of emotion [24]. In animal models, tactile stimulation leads to activation of oxytocin neurons, which is related to social behavior, stress response, and modulation of anxiety and pain [23].

In humans, gentle skin stroking in early infancy has been shown to result in activation of both the postcentral gyrus and the posterior insular cortex, representing discriminative somatosensory processing as well as socio-affective processing, respectively [27]. The activation pattern depends on the type of touch: slow frequency stroking, which is typical of affectionate touch given by parents, results in activation of the insular cortex, while fast stroking does not [10]. This is of clinical relevance. A recent review collected evidence that early neonatal affectionate caregiver touch has broad effects on sensory function, adaptive regulation of stress and arousal via the autonomic nervous system, immune function, social behavior and bonding and regulation of reward-seeking behavior [5]. These emotional consequences of touch seem to be specifically mediated by $\mathrm{CT}$ afferents.

Similar findings extend into later life: in preschool children the frequency of parental affectionate touch is related to resting activity and connectivity of the "social brain", according to a functional magnetic resonance imaging (MRI) study [3]. Another step later in life, affectionate touch modulates brain processing of pain and subjective pain perception, as was demonstrated in a quantitative electroencephalogram (EEG) study [20]; however, not only the type of touch but also the social context is relevant for emotional processing of stimuli. In a functional MRI study, affective touch was perceived as pleasant and reward-related brain areas were stimulated only if probands assumed that this touch was performed by their partner. Intranasal oxytocin did not increase activation of reward-related brain areas if probands believed that the touch was performed by a stranger [14]. This study cautioned that results of studies with touch provided by parents to infants may not be transferable to a setting where professional caregivers provide touch-based treatment to strange persons. This problem may disappear in repeated sessions of touch-based therapy when the therapist factor is held constant, i.e. no change of therapist between therapy sessions.

Most of these neurobiological studies investigated touch administered by relatives (parents of newborns, partners of young adults) rather than treatment by professional caregivers and most studies evaluated effects of touch on neurode- 
velopment rather than on treatment of psychiatric conditions.

\section{Implications for touch-based therapy in psychiatry of old age}

New findings in the field of neurobiology of touch shed a new light on potential mechanisms of action of touch-based therapy. The neurobiological finding of a distinct neuronal pathway mediating effects of social and affective touch, in contrast to discriminative touch may in part explain why clinical studies and clinical experiences with touch-based therapy are ambiguous. Despite weak effects on objective endpoints in clinical studies, touchbased therapy is widely accepted by patients. Clinical studies tend to provide more beneficial results if subjective, emotional and psychological endpoints are targeted. Unfortunately, while neurobiological evidence extends from the effects of touch in early infancy into young adulthood, only limited evidence is emerging for old age.

This strongly suggests new directions for further research and for clinical application of touch-based treatments:

- Endpoints of studies on the effects of touch-based treatment should comprise well-defined psychological variables.

- Studies should include older adults.

- The background of social deprivation, which is frequently present in old age, should be considered.

- Psychiatric disorders of old age appear to be promising indications for the use of touch-based treatment and need to be evaluated in prospective clinical trials.

- The setting and interpersonal relationship between patients and therapeutic personnel need to be taken into account. This also includes questions of ethics and of professionality: how much intimacy should be considered appropriate in the treatment of older patients with psychiatric disorders?

One recent promising finding is the efficacy of massage and touch therapy as a treatment for depressive symptoms in patients with dementia [30]. Massage therapy alone or in combination with music therapy has also been proven to reduce agitated and aggressive behavior in dementia [29]. A similar promising but less well studied treatment concept is basic stimulation (basale Stimulation), which has been broadly used in nursing homes in German language countries [12]. Traditional physical therapy does not work with touch-based interventions alone but places them into context with various other stimuli. such as electrical or thermal interventions. Although transmission of temperature signalling is distinct from CT afferent signalling, the combination of different interventions can contribute to the effects. One recent clinical study gives some hope that treatment of psychiatric disorders can also benefit from interventions which target slow unmyelinated C-fibres: hyperthermic baths have been shown to be an effective adjuvant therapy in depression [22].

\section{Conclusion}

In summary, massage and touch-based therapy is a very heterogeneous group of interventions. It is mainly applied, but not limited to disorders of the musculoskeletal system. Evidence from prospective clinical trials for its efficacy is low and of low quality, mainly due to problems with precise definition of interventions and to difficulties in designing meaningful control settings for clinical studies. Nevertheless, this type of treatment is well accepted by patients and appears to fulfil a special need.

New findings from neurobiological and neurodevelopmental studies suggest that social and affective touch is processed by a distinct system of neural transmission, involving C-LTMR. This finding provides a possible mechanism of action for touch-based interventions in order to target psychiatric symptoms. Meta-analyses demonstrated significant clinical benefits of touch-based interventions on depressive and aggressive symptoms of dementia. Given the limited effects of pharmacological interventions and the high vulnerability of geriatric patients to adverse drug events, touch-based interventions should be generously applied in older patients with geriatric symptoms. Additional research is needed for further design and evaluation of touch-based treatment.

\section{Corresponding address}

PD Dr. Daniel Kopf

Klinik für Geriatrie, Endokrinologie und

Diabetologie, Geriatrischer Schwerpunkt, RKH-

Kliniken Ludwigsburg/Bietigheim

Riedstr. 12, 74321 Bietigheim-Bissingen,

Germany

daniel.kopf@rkh-kliniken.de

Acknowledgements. Part of this paper was presented at the 2019 GeriNet Symposium in Hamburg in cooperation with Mrs. Manja Tavaglione.

\section{Declarations}

Conflict of interest. D. Kopf declares that he has no competing interests.

Ethical standards. For this article no studies with human participants or animals were performed by the author. All studies performed were in accordance with the ethical standards indicated in each case.

\section{References}

1. Abraira VE, Ginty DD (2013) The sensory neurons of touch. Neuron 79(4):618-639. https://doi.org/10. 1016/j.neuron.2013.07.051

2. Banerjee D, Vasquez V, Pecchio M, Hegde ML, Ks Jagannatha R, Rao TS (2021) Biopsychosocial intersections of social/affective touch and psychiatry: Implications of "touch hunger" during COVID-19. Int J Soc Psychiatry 24:20764021997485. https:// doi.org/10.1177/0020764021997485

3. Brauer J, Xiao Y, Poulain T, Friederici AD, Schirmer A (2018) Frequency of maternal touch predicts resting activity and connectivity of the developing social brain. Cereb Cortex 28(2):692. https://doi. org/10.1093/cercor/bhx323

4. Candy B, Armstrong M, Flemming K, Kupeli $\mathrm{N}$ Stone P, Vickerstaff V, Wilkinson S (2020) The effectiveness of aromatherapy, massage and reflexology in people with palliative care needs: a systematic review. Palliat Med 34(2):179-194. https://doi.org/10.1177/0269216319884198

5. Carozza S, Leong V (2021) The role of affectionate Caregiver touch in early neurodevelopment and parent-infant interactional synchrony. Front Neurosci. https://doi.org/10.3389/fnins.2020. 613378

6. Cascio CJ, Moore D, McGlone F (2019) Social touch and human development. Dev Cogn Neurosci 35:5-11. https://doi.org/10.1016/j.dcn.2018.04. 009

7. Field T (2016) Massage therapy research review. Complement Ther Clin Pract 24:19-31. https://doi. org/10.1016/j.ctcp.2016.04.005

8. Furlan AD, Giraldo M, Baskwill A, Irvin E, Imamura M (2015) Massage for low-back pain. Cochrane Database Syst Rev. https://doi.org/10.1002/ 14651858.CD001929.pub3

9. Grober J (1953) Kutiviszerale Reflexe und physikalische Therapie [Cutaneo-visceral reflexes and physical therapy]. Dtsch Med Wochenschr 78(40):1357-1359. https://doi.org/10.1055/s0028-1114948

10. Jönsson EH, Kotilahti $K$, Heiskala J, Wasling HB, Olausson H, Croy I, Mustaniemi H, Hiltunen P, 
Tuulari JJ, Scheinin NM, Karlsson L, Karlsson H, Nissilä I (2018) Affective and non-affective touch evoke differential brain responses in 2-month-old infants. Neuroimage 169:162-171. https://doi. org/10.1016/j.neuroimage.2017.12.024

11. Kefauver JM, Ward AB, Patapoutian A (2020) Discoveries in structure and physiology of mechanically activated ion channels. Nature 587(7835):567-576. https://doi.org/10.1038/ s41586-020-2933-1

12. Kohler M, Mullis J, Burgstaller M, Schwarz J, Saxer S (2018) Effects of basal touch on challenging behaviour during personal hygiene activities in nursing home residents with dementia: a mixed methods study. Klin Pflegeforsch 4:13-26. https:// doi.org/10.6094/KlinPfleg.4.13

13. Kolster BC (2006) Geschichte der Massage. In: Kolster BC (ed) Massage. Physiotherapie Basics. Springer, Berlin, Heidelberg https://doi.org/10. 1007/3-540-34290-7_1

14. Kreuder AK, ScheeleD, Wassermann L, WollseiferM, Stoffel-Wagner B, Lee MR, Hennig J, Maier W, Hurlemann R (2017) How the brain codes intimacy: the neurobiological substrates of romantic touch. Hum Brain Mapp 38(9):4525-4534. https://doi. org $/ 10.1002 / \mathrm{hbm} .23679$

15. Lavazza C, Galli M, Abenavoli A, Maggiani A (2021) Sham treatment effects in manual therapy trials on back pain patients: a systematic review and pairwise meta-analysis. BMJ Open 11(5):e45106. https://doi.org/10.1136/bmjopen-2020-045106

16. Ledford H, Callaway E (2021) Medicine Nobel goes to scientists who discovered biology of senses. Nature 598:246. https://doi.org/10.1038/d41586021-01283-6

17. Li YH, Wang FY, Feng CQ, Yang XF, Sun YH (2014) Massage therapy for fibromyalgia: a systematic review and meta-analysis of randomized controlled trials. PLoS ONE 9(2):e89304. https://doi.org/10. 1371/journal.pone.0089304

18. Lu LC, Lan SH, Hsieh YP, Lin LY, Chen JC, Lan SJ (2020) Massage therapy for weight gain in preterm neonates: A systematic review and meta-analysis of randomized controlled trials. Complement Ther Clin Pract 39:101168. https://doi.org/10.1016/j. ctcp.2020.101168

19. McGlone F, Wessberg J, Olausson H (2014) Discriminative and affective touch: sensing and feeling. Neuron 82(4):737-755. https://doi.org/ 10.1016/j.neuron.2014.05.001

20. von Mohr M, Krahé C, Beck B, Fotopoulou A (2018) The social buffering of pain by affective touch: a laser-evoked potential study in romantic couples. Soc Cogn Affect Neurosci 13(11):1121-1130. https://doi.org/10.1093/scan/nsy085

21. Mueller SM, Grunwald M (2021) Effects, side effects and contraindications of relaxation massage during pregnancy: a systematic review of randomized controlled trials. J Clin Med 10(16):3485. https:// doi.org/10.3390/jcm10163485

22. Naumann J, Kruza I, Denkel L, Kienle G, Huber $R$ (2020) Effects and feasibility of hyperthermic baths in comparison to exercise as add-on treatment to usual care in depression: a randomised, controlled pilot study. BMC Psychiatry 20(1):536. https://doi. org/10.1186/s12888-020-02941-1

23. Okabe S, Yoshida M, Takayanagi Y, Onaka T (2015) Activation of hypothalamic oxytocin neurons following tactile stimuli in rats. Neurosci Lett 600:22-27

24. Olausson $\mathrm{H}$, Lamarre $\mathrm{Y}$, Backlund $\mathrm{H}$, Morin $\mathrm{C}$, Wallin BG, Starck G, Ekholm S, Strigo I, Worsley K, Vallbo $A B$, Bushnell MC (2002) Unmyelinated tactile afferents signal touch and project to insular

\section{Massage und berührungsbasierte Therapie. Klinische Evidenz, Neurobiologie und Anwendung bei älteren Patienten mit psychiatrischen Symptomen}

Hintergrund: Massage und berührungsbasierte Therapie erfreuen sich großer Beliebtheit trotz begrenzter Evidenz von klinischen Studien, die hohen formalen Qualitätsansprüchen genügen. Dieser Artikel gibt eine Übersicht über Begründung und klinische Effektivität von berührungsbasierten Therapien bei älteren Patienten mit psychiatrischen Erkrankungen.

Methoden: Narrativer Review. Literatur wurde über PubMed mit folgenden Stichworten gesucht: "massage “, "social touch", ,affective touch", "clinical trial“ und „metaanalysis". Referenzen der auf diese Weise identifizierten Literatur wurden ebenfalls herangezogen.

Ergebnisse: Evidenz aus klinischen Studien mit erwachsenen Patienten, die an überwiegend chronischen Erkrankungen des Bewegungsapparats leiden, spricht für eine signifikante kurzfristige symptomatische Besserung der Beschwerden. Die Wirksamkeit ist aber nur kurz anhaltend. Die Bewertung der Studien ist schwierig, da viele verschiedene Therapieformen bei unterschiedlichen Krankheitsbildern mit unterschiedlichen Endpunkten untersucht werden. Zudem ist es schwierig bis unmöglich, verblindete Kontrolltherapien zu definieren. Die Evidenz scheint für eine bessere Wirksamkeit auf psychologische und subjektive Endpunkte wie Schmerzen und Lebensqualität zu sprechen. In den letzten Jahren wurde ein neuronales Netzwerk für soziale und affektive Verarbeitung von Berührung identifiziert, das sich durch definierte Afferenzen von niedrigschwelligen Mechanorezeptoren über C-Fasern definiert. Diese projizieren zum Inselkortex und zum limbischen System. Diese Kenntnisse können helfen, ältere Therapiestrategien für ältere Menschen mit psychiatrischen Erkrankungen und Begleitsymptomen auf ihre Wirksamkeit und ihre Wirkmechanismen hin zu untersuchen, neu zu bewerten und neue Therapieoptionen, die auf Berührung und Massage beruhen, zu entwickeln. Studien bei Patienten mit Altersdepression und depressiven Symptomen bei Demenz haben bereits vielversprechende Ergebnisse erbracht.

Schlussfolgerung: Das neurobiologische Netzwerk für affektive und soziale Berührung könnte die Basis für einen Wirkmechanismus berührungsbasierter Therapien bei psychiatrischen Patienten in höherem Alter sein. Dieser Wirkmechanismus könnte dazu führen, dass berührungsbasierte Therapieoptionen in Zukunft besser untersucht werden und ihre Effektivität als Therapieoption für psychiatrische Störungen bei älteren Menschen geprüft werden kann.

\section{Schlüsselwörter}

Demenz · Mechanorezeptoren · C-Fasern · Soziale Berührung · Geriatrische Depression

cortex. Nat Neurosci 5(9):900-904. https://doi. org/10.1038/nn896

25. Taheri PA, Goudarzi Z, Shariat M, Nariman S, Matin EN (2018) The effect of a short course of moderate pressure sunflower oil massage on the weight gain velocity and length of NICU stay in preterm infants. Infant Behav Dev 50:22-27. https://doi.org/10.1016/j.infbeh.2017.11.002

26. Torres R, Ribeiro F, Duarte AJ, Cabri JM (2012) Evidence of the physiotherapeutic interventions used currently after exercise-induced muscle damage: systematic review and meta-analysis. Phys Ther Sport 13(2):101-114. https://doi.org/10. 1016/j.ptsp.2011.07.005

27. Tuulari JJ, Scheinin NM, Lehtola S, Merisaari H, Saunavaara J, Parkkola R, Sehlstedt I, Karlsson L, Karlsson H, Björnsdotter M (2019) Neural correlates of gentle skin stroking in early infancy. Dev Cogn Neurosci 35:36-41. https://doi.org/10.1016/j.dcn. 2017.10.004
28. Vickers A, Ohlsson A, Lacy JB, Horsley A (2004) Massage for promoting growth and development of preterm and/or low birth-weight infants. Cochrane Database Syst Rev. https://doi.org/10. 1002/14651858.CD000390.pub2

29. Watt JA, Goodarzi Z, Veroniki AA, Nincic V, Khan PA, Ghassemi M, Thompson Y, Tricco AC, Straus SE (2019) Comparative efficacy of interventions for aggressive and agitated behaviors in dementia: a systematic review and network meta-analysis. Ann Intern Med 171(9):633-642. https://doi.org/10. 7326/M19-0993

30. Watt JA, Goodarzi Z, Veroniki AA, Nincic V, Khan PA, Ghassemi M, Lai Y, Treister V, Thompson Y, Schneider R, Tricco AC, Straus SE (2021) Comparative efficacy of interventions for reducing symptoms of depression in people with dementia: systematic review and network meta-analysis. BMJ 372:n532. https://doi.org/10.1136/bmj.n532 